\title{
Multimodal Local Opioid Prescribing Intervention Outcomes in Chronic Noncancer Pain Management
}

\author{
Natalia P. Arizmendez, MD, Fabiana Kotovicz, MD, Jessica J. F. Kram, MPH, \\ and Dennis J. Baumgardner, MD
}

Background: Opioid misuse in the United States has made it challenging for physicians to treat chronic noncancer pain (CNCP). We implemented an educational program aimed at promoting safe opioid prescribing practices in hopes of increasing the level of appropriateness associated with prescribing opioids for CNCP.

Methods: We conducted a quality-improvement study with a retrospective chart review of adult patients who were prescribed opioids for CNCP for at least 90 consecutive days at 2 academic primary care clinics. Patients were reviewed at baseline (July 2014-May 2015) and after initial interventions (January 2016-June 2016; ie, following multimodal educational activities on appropriate opioid prescription implemented from June 2015-December 2015). An opioid appropriateness score was calculated based on documentation of 9 items. Categorical variables were analyzed with Fisher exact tests and continuous variables by 2 -sample $t$ tests and regression analysis. Binary logistic regression was used for multivariable modeling. Mann-Whitney test was used to compare appropriateness scores before and after intervention.

Results: A total of 177 and 96 patients were evaluated at baseline and postintervention, respectively. Patient demographic characteristics were not statistically different. Overall, postintervention level of appropriateness was significantly different from preintervention $(P<.0001)$, with means increasing from 5.54 preintervention to 6.29 postintervention. Both clinics had significant improvement from baseline (both $P$ values <.003).

Conclusions: Clinician education on best practices while treating CNCP is associated with an increase in the level of opioid use appropriateness. (J Am Board Fam Med 2019;32:559-566.)

Keywords: Chronic Pain Management, Family Physicians, Logistic Models, Opioid Analgesics, Opioid-Related Disorders, Patient Safety, Primary Health Care, Quality Improvement, Retrospective Studies

Chronic noncancer pain $(\mathrm{CNCP})$ is a complex experience that affects more than $26 \%$ of Americans. ${ }^{1,2}$ A survey of 16 countries estimated that the prevalence of chronic pain ranged from $12 \%$ to

This article was externally peer reviewed.

Submitted 6 October 2018; revised 27 March 2019; accepted 28 March 2019.

From Aurora Health Care, Department of Family Medicine, Aurora St. Luke's Medical Center, Milwaukee, WI (NPA, FK, DJB); Aurora Health Care, Department of Internal Medicine, Aurora St. Luke's Medical Center, Milwaukee, WI (NPA); Department of Family Medicine and Community Health, University of Wisconsin School of Medicine and Public Health, Madison (FK, JJFK, DJB); Aurora Health Care, Aurora UW Medical Group and Center for Urban Population Health, Aurora Sinai Medical Center, Milwaukee, WI (JJFK, DJB).

Funding: This study was funded in part by the Aurora University of Wisconsin Medical Group, Milwaukee Clinical Faculty Fund.
$30 \% .^{3}$ Although there are similarities in reported chronic pain worldwide, the consumption of opioids in defined daily doses is among the highest in North America. ${ }^{4}$ Physicians across the United States have faced major challenges in managing and treating CNCP, defined as noncancer pain that lasts 90 days or more. For several years, opioids were 1 of the cornerstones in the treatment of CNCP, leading to increased risk of opioid misuse. Despite significant emphasis on opioid use for CNCP over the last 2 decades, recent studies have shown that opioids are no more effective than non-

Conflict of interest: none declared.

Corresponding author: Fabiana Kotovicz, MD, 2801 W Kinnickinnic River Parkway, Suite 250, Milwaukee, WI 53215 (E-mail: fabiana.kotovicz@aurora.org). 
opioid pain medications, and long-term opioid use is associated with decreased odds of recovery and lower quality of life. . $^{2,6}$

More recently, literature has reported changes in physician attitudes and increased reluctance to prescribe opioids. ${ }^{7,8}$ A study conducted by Jamison et al surveyed primary care providers and found that the majority of practitioners were uncomfortable prescribing opioids, especially due to concerns of misuse. ${ }^{8}$ Multiple groups and medical societies have put forth efforts to increase safe and appropriate opioid prescribing in primary care through recommendations in this topic. For example, the American Council of Graduate Medical Education and the American Association of Medical Colleges mandated pain management education and training in residency and medical school. ${ }^{7}$ Moreover, opioid prescribing guidelines have been published to assist physician prescribing decision-making. ${ }^{9}$ In addition, several states have attempted to address this public health issue with initiatives, such as prescription drug monitoring programs and campaigns, to prevent the abuse of opioids and heroin. ${ }^{10}$

The effects of opioid prescribing interventions in primary care, including use of guidelines and education on opioid prescribing best practices, have been described in the literature..$^{2,5-7,11,12}$ Although opioid awareness, increased knowledge, and clinician comfort with prescribing opioids were demonstrated, education has mostly failed to show a significant impact on provider prescribing behavior. ${ }^{2,5-7,11,12}$, and ultimately, the use of guidelines in daily practice remains low. ${ }^{13}$ McCraken et al evaluated the effects on physician practice with 2 training interventions and found that neither had an effect on opioid prescribing. ${ }^{6}$ Similarly, Victor et al noted no improvement in provider prescribing after introducing opioid education and prescribing guidelines. $^{2}$ In contrast, more recent studies, such as Chen et al, have observed a reduction in opioid prescribing rates with educational intervention in combination with opioid prescribing guidelines. ${ }^{5}$ This has provided further support for adjunctive education versus the implementation of guidelines alone. Therefore, the purpose of this project was to determine if educating primary care physicians on safe opioid prescribing practices in an academic setting increases the level of appropriateness of opioid use for CNCP.

\section{Methods}

We obtained a determination of nonhuman subject research from our institutional review board and conducted a quality-improvement study with retrospective chart review at 2 academic family medicine clinics in Milwaukee, Wisconsin. Clinic 1 is located in the south side of Milwaukee and serves a predominately white population $(40.2 \%$ non-Hispanic; $22.1 \%$ Hispanic); clinic 2 is located in central Milwaukee and serves a majority of African American patients (64.4\%). Both clinics serve primarily a low-income patient population (approximately 34,000 patients seen yearly). In addition, within clinic 1 and 2, 25.7\% and $46.1 \%$ of patients are Medicaid recipients, respectively. Their providers are mostly comprised of residents $(67 \% ; 10$ residents per class), with a predominance of females (60\% among faculty members and $72 \%$ among residents). Nonresident providers included 3 nurse practitioners and 12 faculty physicians.

Medical records of all adult ambulatory patients treated with opioids for CNCP for 90 days or more were reviewed. Patients were excluded if their primary care physician was 1 of the investigators or if they were also managed by pain management specialists during the investigated timeframes, July 2014 to May 2015 (preintervention) and January 2016 to $06 / 2016$ (postintervention). If a patient was seen more than once during the studied period, only the last medical encounter note was included. Because our study focused on presence/absence of documentation as well as content, no eligible patients were excluded. Thus, many patients were likely included in both time periods reviewed.

A multicomponent educational intervention from June 2015 to December 2015 included a PowerPoint-style lecture series covering the topics with the following titles: Opioid Physiology and Effects, Identifying Opioid Abuse in Chronic Pain Patients, Interacting with the Drug-Seeking Patient, Pharmacological Approaches to Pain, and Prescribing Opiates Responsibly. Weekly 1-hour lectures were conducted by a national-level expert in the field of pain management with family medicine training. All faculty, residents, and clinic staff from both clinics were invited to attend. The intervention also included development and dissemination of electronic health record tools, routine group e-mails promoting safe opioid prescribing, pocket guides to be used during initial and follow-up appointments 
Figure 1. Are you prescribing opioids inappropriately? Recommendations for chronic noncancer pain (CNCP) management with opioids at initial and follow up visits.

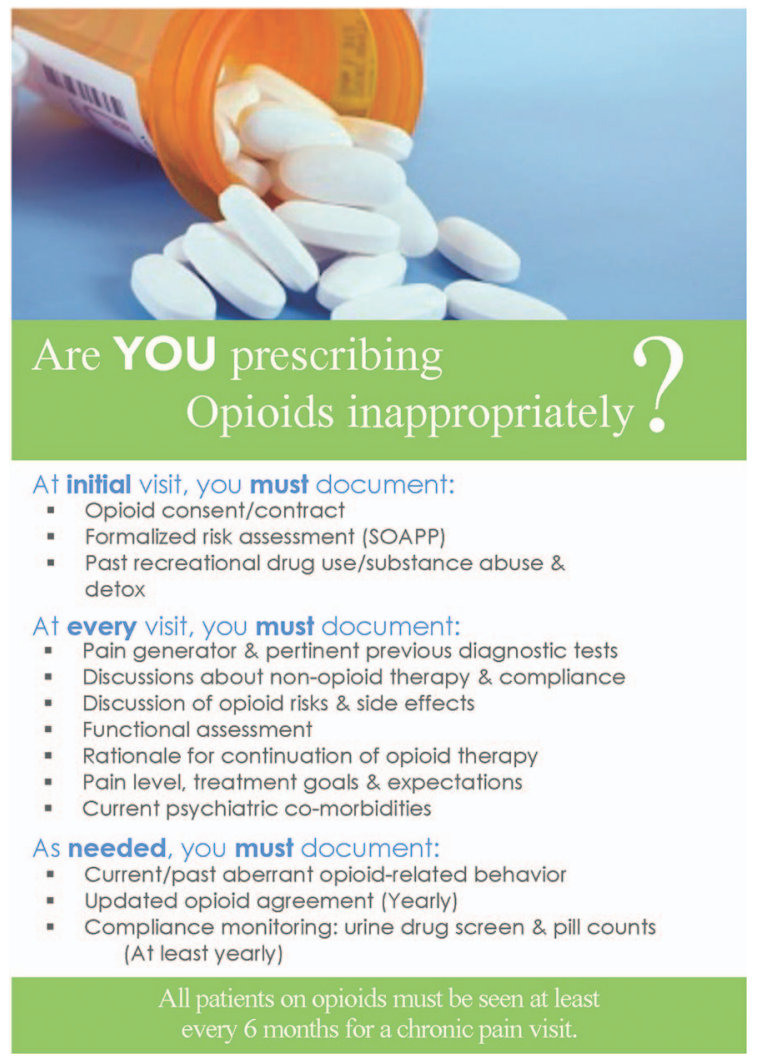

with CNCP patients, and posters, which were placed near resident and faculty workstations (Figures 1 and 2). Pocket cards and posters contained information on the appropriate use of opioids for $\mathrm{CNCP}$, as well as how to adequately order and interpret urine drug screens.

An opioid prescription appropriateness score (our primary outcome of interest) was developed based on best evidence available, including the State of Wisconsin Medical Board Opioid Prescribing Recommendations, as well as our institutional opioid prescription guideline. Its scoring items highly aligned with recommendations from the Centers for Disease Control of Prevention (CDC) Guideline for Prescribing Opioids for Chronic Pain, reinforcing its validity. ${ }^{9}$ It was used to calculate, with equal weighting, documentation of 9 items with comparison between patients seen before and after the intervention. Table 1 displays the definition for each of the 9 items associated with the level of appropriateness. In addition, health-related and sociodemographic data were collected to further characterize our CNCP patient population (Table 2).

All statistical analyses were performed using Minitab statistical software (version 13; State College, PA). Categorical variables were analyzed with Fisher exact tests. Continuous variables were analyzed with 2-sample $t$ tests and regression analysis. Binary logistic regression was used for multivariable modeling. In addition, Mann-Whitney test was used to compare appropriateness scores before and after intervention.

\section{Results}

A total of 177 and 96 patients were evaluated at baseline and postintervention, respectively. Patient characteristics and demographics for both populations are described in Table 2. In the baseline and postintervention period, the number of patients identified at clinic 1 and clinic $2 \operatorname{did}$ not $\operatorname{differ}(P=$ $.574)$. Overall, patients in both the baseline and postintervention periods were of mean age 55.5 years versus 56.3 years $(P=.613)$, predominantly female $(62.7 \%$ vs $64.6 \%, P=.794)$, and of nonwhite race/ethnicity $(56.5 \%$ vs $55.2 \%, P=.899)$. Depression (71.2\% vs $75.0 \%, P=.571)$ and anxiety (63.8\% vs $68.8 \%, P=.427$ ) were the most prevalent comorbid psychiatric conditions at baseline and postintervention, respectively.

The most common sites treated for pain at baseline and postintervention included the back, neck, and thoracic areas $(65.0 \%$ vs $68.8 \%, P=.592)$, as well as limb pain, which includes knee, hand, and foot pain $(51.4 \%$ vs $46.9 \% ; P=.527)$. In addition, there was a moderate prevalence of neuropathy among patients in both periods (15.3\% vs $29.2 \%$ ). There was a significant increase in the proportion of patients with pain associated with neuropathy $(P=.010)$ and a significant decrease in the proportion of patients with pain associated with fibromyalgia (13.6\% vs $4.2 \%, P=.020)$ between periods. Both oxycodone and hydrocodone were the most commonly used opioids for more than 90 days for treatment of chronic noncancer pain.

Overall, a statistically significant difference in the level of appropriateness score between the baseline and postintervention period was identified (5.54 vs $6.29, P<.001$; Table 1$)$. Similar significant differences were seen at each clinic $(5.58$ vs 6.25 , $P=.001 ; 5.46$ vs $6.38, P=.003)$. Apart from consulting specialists if indicated, there was an im- 
Figure 2. Urine drug screen information sheet. Detailed information on substances tested according to type of urine drug screen ordered.

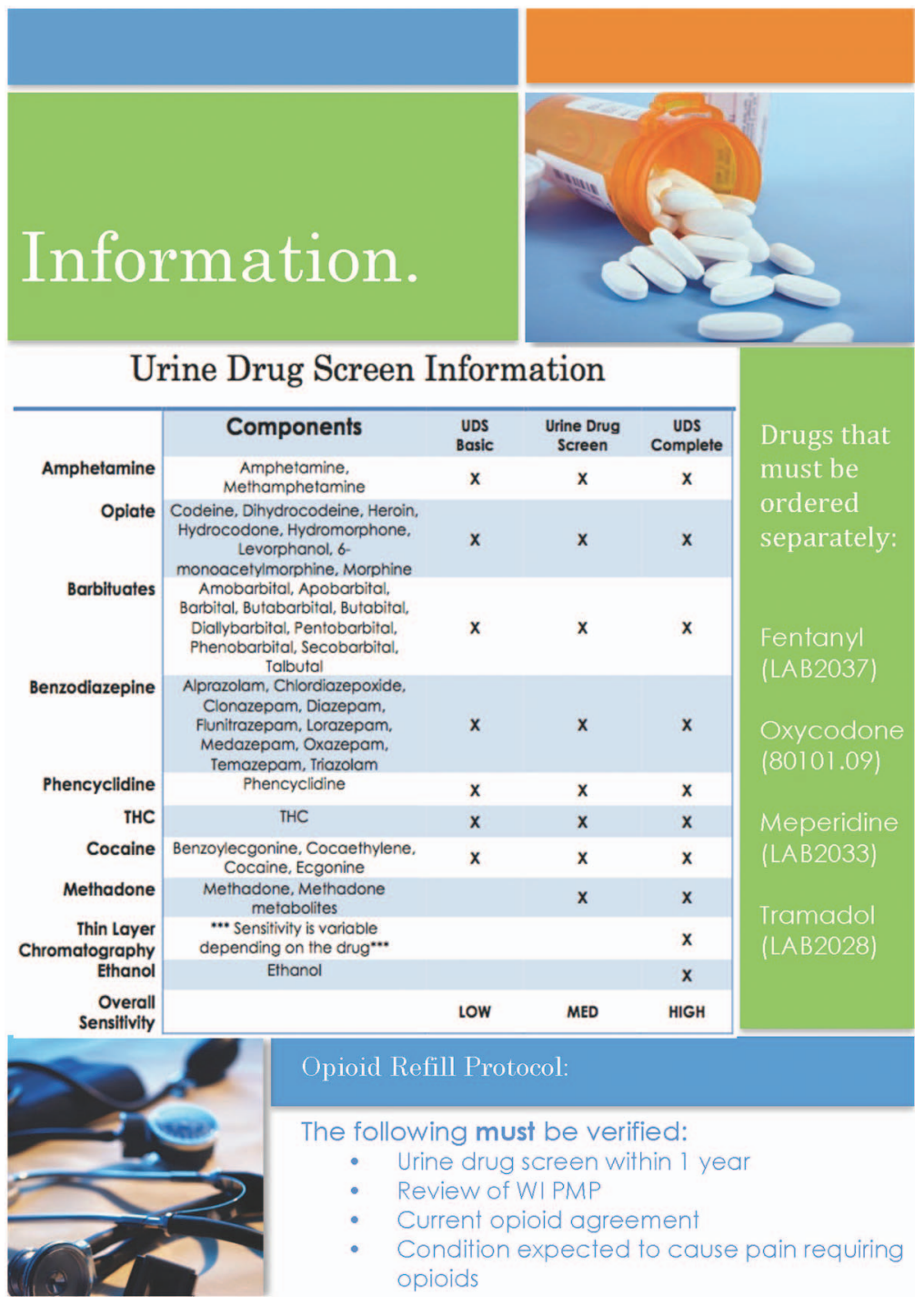

provement in each item used to assess the level of appropriateness. The discussion of expectations and therapeutic goals $(P<.001)$, as well as the use of nonpharmacologic therapies $(P=.023)$, including osteopathic manipulation and physical therapy for CNCP treatment, significantly improved (Table 1).

\section{Discussion}

Chronic pain is a global challenge. Opioids, prescribed mainly by primary care providers, are often used to treat chronic pain but, as previously discussed, are associated with various risks. ${ }^{14,15}$ Prior literature has failed to strongly support the use of education to improve opioid management and pre- scribing practices in an ambulatory setting. ${ }^{2,6,12,13}$ Many studies have shown that well-designed training methods can improve knowledge of pain management and opioid prescribing, but preserving and maintaining behavioral changes in actual practice seem to be more difficult. ${ }^{6}$ In the United Kingdom, McCracken et al observed no significant difference in practices after implementing 2 unique training interventions and opioid prescribing guidelines. ${ }^{6}$ Effects were measured immediately following training and after 2 weeks. Positive impacts of education were seen in conjunction to regulatory measures by Kahan et al; however, their study failed to observe a change in opioid prescribing practices after completion of the 2-day opioid prescribing 
Table 1. Documented Items Required to Determine the Level of Appropriateness for Opioid Prescribing Preintervention and Postintervention among Patients with Chronic Noncancer Pain

\begin{tabular}{|c|c|c|c|c|}
\hline Item & $\begin{array}{l}\text { Preintervention } \\
\qquad(\mathrm{N}=177)\end{array}$ & $\begin{array}{l}\text { Postintervention } \\
\qquad(\mathrm{N}=96)\end{array}$ & $P$ Value & Further Definitions \\
\hline $\begin{array}{l}\text { Overall level of appropriateness score, mean } \\
\text { (SD) }\end{array}$ & $5.54(1.23)$ & $6.29(1.26)$ & $<.001$ & $\begin{array}{l}\text { Opioid appropriateness score } \\
\text { (out of nine) was } \\
\text { calculated based on the } \\
\text { number of documented } \\
\text { items described below. }\end{array}$ \\
\hline \multicolumn{5}{|l|}{ Documented items required: } \\
\hline (1) Use of nonpharmacologic methods, N (\%) & $129(72.9)$ & $82(85.4)$ & .023 & $\begin{array}{l}\text { Utilized either physical } \\
\text { therapy or osteopathic } \\
\text { manipulative treatment. }\end{array}$ \\
\hline (2) Specialist consultation, N (\%) & $126(71.2)$ & $66(68.8)$ & .680 & $\begin{array}{l}\text { Specialist consultation } \\
\text { warranted if on } \\
\text { methadone, }>120 \\
\text { morphine equivalents, or } \\
>2 \text { psychiatric conditions. }\end{array}$ \\
\hline $\begin{array}{l}\text { (3) Imaging/EMG/labs to identify pain } \\
\text { generator, N (\%) }\end{array}$ & $137(77.4)$ & $80(83.3)$ & .275 & $\begin{array}{l}\text { For the purpose of } \\
\text { identifying CNCP being } \\
\text { treated with opioids. }\end{array}$ \\
\hline (4) Use of nonopioid medications, N (\%) & $172(97.2)$ & $95(99.0)$ & .669 & $\begin{array}{l}\text { For the purpose of } \\
\text { identifying CNCP being } \\
\text { treated with opioids. }\end{array}$ \\
\hline $\begin{array}{l}\text { (5) Visit to discuss CNCP at least every } 6 \\
\text { months, N (\%) }\end{array}$ & $160(90.4)$ & $90(93.8)$ & 0.494 & \\
\hline $\begin{array}{l}\text { (6) Pain level/therapeutic/functional goals } \\
\text { discussions, N (\%) }\end{array}$ & $56(31.6)$ & $66(68.8)$ & $<.001$ & $\begin{array}{l}\text { Discussed during the last } \\
\text { patient's medical } \\
\text { encounter for CNCP. }\end{array}$ \\
\hline (7) UDS within last year, N (\%) & $29(16.4)$ & $24(25.0)$ & .109 & \\
\hline $\begin{array}{l}\text { (8) Pain contract/agreement within past year, } \\
\text { N (\%) }\end{array}$ & $9(5.1)$ & $12(12.5)$ & .034 & \\
\hline $\begin{array}{l}\text { (9) Documented details on drug use, } \\
\text { substance abuse or detox, N (\%) }\end{array}$ & $162(91.5)$ & $89(92.7)$ & .819 & $\begin{array}{l}\text { At any time prior to or at } \\
\text { the reviewed medical } \\
\text { encounter. }\end{array}$ \\
\hline
\end{tabular}

EMG, electromyogram; CNCP, chronic noncancer pain; SD, standard deviation; UDS, urine drug screen.

course. ${ }^{12}$ In our study, we implemented an extensive multimodal training program for 7 months, which is, to our knowledge, the longest published to date.

Overall, the majority of our patients $(65 \%$ to $68 \%)$ had documented thoracic, back, and neck pain, which correlates with rates in the general US population. ${ }^{16,17}$ Braden et al noticed an increase in the rate of opioid use in patients with multiple pain diagnoses. ${ }^{16}$ Many of those in our study population indeed had an overlap of different types of pain, with limb (51\%) and shoulder (21\%) following back pain. High incidences of aberrant patterns, such as illegal drug use and opioid misuse, are often associated with mental illness and chronic pain diagnoses. ${ }^{6,18-23}$ The lifetime prevalence of depression in our studied population was greater than $70 \%$. Therefore, a thorough mental health screening should be performed before initiating opioids.
In comparison to several other studies, we collected information on the quantity of opioid prescribed over the previous 90 days from the last clinical encounter to manage CNCP. ${ }^{5,12,16}$ The mean average doses of opioid on MDEs were 38 and 31 preintervention and postintervention, with a median average of 15 in both periods. In our literature review, higher MDEs are reported in those with mental health or substance use disorders. ${ }^{16}$

Notably, major recommendations for safe opioid prescribing were publicized by the CDC during the second half of this study and the topic of opioid epidemic became more apparent in the media, ${ }^{9}$ which could have impacted the provider's chronic opioid prescribing practices in addition to our intervention. Even though our model for opioid prescribing was based mostly on expert opinion and developed before publication of the CDC 2016 Guidelines, ${ }^{9}$ it aligned with those of the CDC's and 
Table 2. Characteristics and Demographics of Chronic Noncancer Patients Preintervention and Postintervention

\begin{tabular}{|c|c|c|c|}
\hline Characteristic & $\begin{array}{l}\text { Preintervention } \\
\quad(\mathrm{N}=177)\end{array}$ & $\begin{array}{l}\text { Postintervention } \\
\quad(\mathrm{N}=96)\end{array}$ & $P$ Value \\
\hline Age (mean) & 55.5 & 56.3 & 613 \\
\hline Nonwhite race, $\mathrm{N}(\%)$ & $100(56.5)$ & $53(55.2)$ & .899 \\
\hline Female, N (\%) & $111(62.7)$ & $62(64.6)$ & .794 \\
\hline History of severe chronic obstructive pulmonary disease, N (\%) & $7(4.0)$ & $6(6.3)$ & .390 \\
\hline History of sleep apnea, N (\%) & $51(28.8)$ & $31(32.3)$ & .582 \\
\hline History of illegal drugs or alcohol abuse, N (\%): & $53(30.0)$ & $28(29.2)$ & 1.000 \\
\hline Heroin, N (\%) & $7(4.0)$ & $1(1.0)$ & .267 \\
\hline Cocaine, N (\%) & $16(9.0)$ & $8(8.3)$ & 1.000 \\
\hline Alcohol, N (\%) & $22(12.4)$ & $10(10.4)$ & .697 \\
\hline Marijuana, N (\%) & $29(16.4)$ & $16(16.7)$ & 1.000 \\
\hline History of addiction to opioid, N (\%) & $18(10.2)$ & $7(7.3)$ & .514 \\
\hline History of opioid overdose, N (\%) & $7(4.0)$ & $5(5.2)$ & .759 \\
\hline \multicolumn{4}{|l|}{ Psychiatric conditions: } \\
\hline Posttraumatic stress disorder, N (\%) & $10(5.6)$ & $7(7.3)$ & .607 \\
\hline Schizophrenia, N (\%) & $11(6.2)$ & $7(7.3)$ & .800 \\
\hline Bipolar, N (\%) & $14(7.9)$ & $8(8.3)$ & 1.000 \\
\hline Panic, N (\%) & $37(20.9)$ & $24(25.0)$ & .450 \\
\hline Anxiety, N (\%) & $113(63.8)$ & $66(68.8)$ & .427 \\
\hline Depression, N (\%) & $126(71.2)$ & $72(75.0)$ & .571 \\
\hline \multicolumn{4}{|l|}{ Current type of pain: } \\
\hline Neuropathy, N (\%) & $27(15.3)$ & $28(29.2)$ & .010 \\
\hline Abdominal, N (\%) & $7(4.0)$ & $7(7.3)$ & .258 \\
\hline Fibromyalgia, N (\%) & $24(13.6)$ & $4(4.2)$ & .020 \\
\hline Shoulder, N (\%) & $37(20.9)$ & $13(13.5)$ & .144 \\
\hline Pelvic/hip, N (\%) & $25(14.1)$ & $11(11.5)$ & .580 \\
\hline Limb, N (\%) & $91(51.4)$ & $45(46.9)$ & .527 \\
\hline Back/neck/thoracic, N (\%) & $115(65.0)$ & $66(68.8)$ & .592 \\
\hline Headache, N (\%) & $4(2.3)$ & $4(4.2)$ & .458 \\
\hline \multicolumn{4}{|l|}{ Opioids used: } \\
\hline Oxycodone, N (\%) & $76(42.7)$ & $39(40.6)$ & .798 \\
\hline Hydrocodone, N (\%) & $63(35.4)$ & $31(32.3)$ & .689 \\
\hline Tramadol, N (\%) & $47(26.6)$ & $28(29.2)$ & .672 \\
\hline Morphine, N (\%) & $19(10.7)$ & $11(11.5)$ & .842 \\
\hline Fentanyl, N (\%) & $4(2.2)$ & $4(4.2)$ & .457 \\
\hline Methadone, N (\%) & $3(1.7)$ & $1(1.0)$ & 1.000 \\
\hline Codeine, N (\%) & $1(0.6)$ & $2(2.1)$ & .283 \\
\hline Morphine dose equivalent (mean) & 37.9 & 31.3 & .363 \\
\hline \multicolumn{4}{|l|}{ Nonopioids used: } \\
\hline Acetaminophen, N (\%) & $61(34.5)$ & $41(42.7)$ & .192 \\
\hline Nonsteroidal anti-inflammatory drug, N (\%) & $116(65.5)$ & $66(68.8)$ & .687 \\
\hline Topical, N (\%) & $62(35.0)$ & $41(42.7)$ & .240 \\
\hline Muscle relaxant, N (\%) & $83(46.9)$ & $57(59.4)$ & .057 \\
\hline Antidepressant, N (\%) & $98(55.4)$ & $59(61.5)$ & .370 \\
\hline Antiepileptic, N (\%) & $76(42.9)$ & $49(51.0)$ & .206 \\
\hline
\end{tabular}




\begin{tabular}{lccc}
\hline Characteristic & $\begin{array}{c}\text { Preintervention } \\
(\mathrm{N}=177)\end{array}$ & $\begin{array}{c}\text { Postintervention } \\
(\mathrm{N}=96)\end{array}$ & $P$ Value \\
\hline Concomitant benzodiazepine use, N (\%) & $37(20.9)$ & $29(30.2)$ & .103 \\
Specialist for current pain: & & & \\
$\quad$ Physical therapy, N (\%) & $126(71.2)$ & $74(77.1)$ & .319 \\
Osteopathic manipulative treatment, N (\%) & $104(58.8)$ & $49(51.0)$ & .251 \\
Surgery, N (\%) & $8(4.5)$ & $7(8.3)$ & .279 \\
Gastrointestinal, N (\%) & $6(3.4)$ & $12(12.5)$ & .232 \\
Podiatry, N (\%) & $14(7.9)$ & $12(12.5)$ & .280 \\
Neurologist, N (\%) & $19(10.7)$ & $36(37.9)$ & .692 \\
Behavioral health, N (\%) & $65(36.7)$ & $10(10.4)$ & .896 \\
Rheumatology, N (\%) & $13(7.3)$ & $40(41.7)$ & .373 \\
Pain management, N (\%) & $59(33.3)$ & $37(38.5)$ \\
Orthopedist, N (\%) & $79(44.6)$ & .189 \\
\hline
\end{tabular}

mirrored recommendations by many authors, including Chen et al. ${ }^{5,15}$ During our multimodal educational intervention, checking the prescription drug monitoring program was recommended, but it was not included in the opioid prescribing level of appropriateness due to the inability of accurately determining this measure because our state prescription drug monitoring program was not linked to our electronic medical record at that time. The lack of control subjects as an outcome of harm or misuse of the prescribed opioid was another limitation of this study.

Considering that many authors, such as Victor et al, found a lack of change in opioid prescribing practices after strictly implementing pain-treatment guidelines, ${ }^{2}$ we believe our supplemental 7-month multimodal education, in addition to greater opioid-related risk awareness, provided reinforcement and, therefore, a sustained change in physician practices for opioid prescribing. We can, therefore, support similar interventions in the ambulatory setting.

In conclusion, to our knowledge, this is the first study to use a carefully designed scoring method to measure provider's appropriate opioid prescribing based on guideline recommendations (Table 1). Our results demonstrate the impact of education and opioid prescribing training using a multifaceted and objective scoring system in the level of appropriateness on the use of opioid for CNCP, which to our knowledge was used for the first time in the literature. These results cannot solely be attributed to our educational intervention but are likely also a result of the increase in public and media attention in addition to implementation of nationwide policies addressing the opioid epidemic during our study period.

We would like to acknowledge Kayla Flores, MD, Stephanie McDearmon, MD, Brandon Phelps, DO, Scott Chandler, DO, Alison Perry, DO, Courtney Pokrzywa, and Jesenia Webster for their assistance with chart review. Lastly, we would like to acknowledge Michael McNett, MD, Christopher Klink, Pharm.D, BCPS, and Brian Wallace, MD for their contributions and guidance in relation to this study.

To see this article online, please go to: http://jabfm.org/content/ 32/4/559. full.

\section{References}

1. National Center for Health Statistics. Health, United States 2006, with chartbook on trends in the health of Americans. Available from: https://www. cdc.gov/nchs/data/hus/hus06.pdf. Published 2006.

2. Victor TW, Alvarez NA, Gould E. Opioid prescribing practices in chronic pain management: guidelines do not sufficiently influence clinical practice. J Pain 2009;10:1051-7.

3. Breivik H, Collett B, Ventafridda V, Cohen R, Gallacher D. Survey of chronic pain in Europe: prevalence, impact on daily life, and treatment. Eur J Pain 2006; 10:287-333.

4. International Narcotics Control Board. Opioid consumption map. Available from: https://www.incb.org/ incb/en/narcotic-drugs/Availability/availability.html. Accessed May 28, 2019.

5. Chen JH, Hom J, Richman I, Asch SM, Podchiyska T, Johansen NA. Effect of opioid prescribing guidelines in primary care. Medicine (Baltimore) 2016;95: e4760.

6. McCracken LM, Boichat C, Eccleston C. Training for general practitioners in opioid prescribing for 
chronic pain based on practice guidelines: a randomized pilot and feasibility trial. J Pain 2012;13:32-40.

7. Ury WA, Rahn M, Tolentino V, et al. Can a pain management and palliative care curriculum improve the opioid prescribing practices of medical residents? J Gen Intern Med 2002;17:625-31.

8. Jamison RN, Sheehan KA, Scanlan E, Matthews M, Ross EL. Beliefs and attitudes about opioid prescribing and chronic pain management: survey of primary care providers. J Opioid Manag 2014;10:375-82.

9. Dowell D, Haegerich TM, Chou R. CDC Guidelines for prescribing opioids for chronic pain United States, 2016. JAMA 2016;315:1624-45.

10. Lutheran A. Wisconsin justice department launches anti-heroin campaign. Availabe from: http://archive. jsonline.com/news/crime/wisconsin-justice-departmentlaunches-anti-heroin-campaign-b99106408z1225204812.html. Published September 25, 2013. Accessed January 2016.

11. Schuit KW, Otter R, Stewart R, Sleijfer DT, Meijler WJ, Jong BM. The effects of a postgraduate course on opioid-prescribing patterns of general practitioners. J Cancer Educ 2000;15:214-7.

12. Kahan M, Gomes T, Juurlink DN, et al. Effect of a course-based intervention and effect of medical regulation on physicians' opioid prescribing. Can Fam Physician 2013;59:231-39.

13. Lasser KE, Shanahan C, Parker V, et al. A multicomponent intervention to improve primary care provider adherence to chronic opioid therapy guidelines and reduce opioid misuse: A cluster randomized controlled trial protocol. J Subst Abuse Treat 2015; 60:101-9.

14. Parchman ML, Korff MV, Baldwin LM, et al. Primary care clinic re-design for prescription opioid management. J Am Board Fam Med 2017;30:44-51.
15. Chen JH, Humphreys K, Shah NH, Lembke A. Distribution of opioids by different types of medicare prescribers. JAMA Int Med 2016;176:259-61.

16. Braden JB, Fan MY, Edlund MJ, Martin BC, DeVries A, Sullivan MD. Trends in use of opioids by non-cancer pain type 2000-2005 among Arkansas Medicaid and HealthCore enrollees: results from the TROUP study. J Pain 2008;9:1026-35.

17. Marcus DA. Treatment of nonmalignant chronic pain. Am Fam Physician 2000;61:1331-38.

18. Tölle TR, Sprenger T, Valet M. Opioid prescription in people with mental health problems-what is the way forward? Nat Clin Pract Neurol 2007;3:368-9.

19. Bair MJ, Bohnert AS. Overdoses in patients on opioids: Risks associated with mental health conditions and their treatment. J Gen Intern Med 2015;30: 1051-3.

20. Sullivan MD, Edlund MJ, Zhang L, Unützer J, Wells KB. Association between mental health disorders, problem drug use, and regular prescription opioid use. Arch Intern Med 2006;166:2087-93.

21. Martins SS, Keyes KM, Storr CL, Zhu H, Chilcoat HD. Pathways between nonmedical opioid use/dependence and psychiatric disorders: results from the National Epidemiologic Survey on Alcohol and Related Conditions. Drug Alcohol Depend 2009;103: $16-24$.

22. Fink DS, Hu R, Cerdá M, et al. Patterns of major depression and nonmedical use of prescription opioids in the United States. Drug Alcohol Depend 2015;153:258-64.

23. Davis MA, Lin LA, Liu H, Sites BD. Prescription opioid use among adults with mental health disorders in the United States. J Am Board Fam Med 2017;30:407-17. 